\begin{tabular}{|c|c|c|c|}
\hline $\begin{array}{l}\text { F O U N D A T I O N S } \\
\text { Vol. } 39\end{array}$ & $\begin{array}{c}\text { C O M P U T I N G A N D } \\
(2014)\end{array}$ & D E C I S I O N & $\begin{array}{r}\text { S C I E N C E S } \\
\text { No. } 1\end{array}$ \\
\hline DOI: $10.2478 /$ fcds-2014-0003 & & & $\begin{array}{l}\text { ISSN } 0867-6356 \\
\text { ISSN 2300-3405 }\end{array}$ \\
\hline
\end{tabular}

\title{
THE STUDY OF PROPERTIES OF THE WORD OF MOUTH MARKETING USING CELLULAR AUTOMATA
}

\author{
Agnieszka Kowalska-Styczeń *
}

\begin{abstract}
This article presents the possibility of using cellular automata, to study the properties of word of mouth (w-o-m) marketing. Cellular automata allow to analyze the dynamics of changes in views and attitudes in social groups based on local interactions between people in small groups of friends, family members etc. The proposed paper shows the possibility of modelling the dynamics of word of mouth mechanism, if the basic assumptions of this process are: different size groups where this phenomenon occurs, and varied access to information.

On the competing firms market, the dependence of the w-o-m mechanism dynamics on the model parameters is shown.
\end{abstract}

Keywords: word of mouth marketing, cellular automata, agent based modeling

\section{Introduction}

The study of social systems is frequently aided by the concept of cellular automata (CA) (more information on CA in the paper [1-3]). Cellular automata can be regarded as a special type of ABM (Agent Based Models), which provide a bridge between macro and micro level, and use simulations to search for causal mechanisms of social behaviour [4]. The agents approach is also frequently used because of the limitations posed by traditional research techniques. The example is the Bass innovation diffusion model presented by Rand and Rust [5] and Peres et al. [6], whose generalization with CA was shown in [7, 8]. Proponents of the CA usage in social and economic studies emphasize in particular, that it is possible to test the paradigm of macro-collective behavior based on local relationships in an easy way [9]. A model proposed in this paper has been constructed precisely in this spirit. The special modification of 'classical' approach is here to introduce the mobility of the agent on a two-dimensional lattice in a situation of varied density of agents in the lattice. This allows taking into account (at the level of local relationships) possible diversity of information sources of the w-o-m mechanism on one hand (friends, distant acquaintances, etc.), but also a natural fact of unequal number of close related people and /

* Silesian University of Technology, Faculty Of Organisation And Management 
or acquaintances on the other. It seems that such a modification approaching the model to reality do not substantially alter the simplicity of the CA model approach.

Word of mouth (w-o-m) communication, as shown by numerous studies [10-13] has a significant impact on consumer choices. In certain circumstances, as shown in [14], this type of communication is more effective than other forms of advertising.

Particularly interesting results which are presented in [15] indicate, that w-o-m is the most effective channel of sales growth, if it is created by not very loyal consumers, but also if the relationship is between acquaintances (not friends). It seems that thanks to introduced mobility of agent in the network (not completely filled) in a certain way, the idea of 'consulting with distant friends' can be developed. Because, of the fact, as pointed out in [16], that the influence of w-o-m on ones opinion in the face of weak links is as strong as the impact of 'strong' relationships, it seems possible that the proposed mobility in the model may be the way to map a process of reaching out to opinion of distant friends. The enlargement of a single agent neighbourhood in the lattice (simulations were performed for two neighborhood sizes $r=1$ and $r=2$ ) can be treated similarly. Since this changes the number of sources of information in w-o-m communication, such a parameterization of the model may be a reflection of studies' results presented by Moldovan et al [17].

Determination of some of the w-o-m mechanism properties by the CA type simulation is the main goal of the studies reported below. Experiments designed to study them were based on the selection process of consumers of one of two competing firms on the market (i.e. Coca-Cola and Pepsi, PC and Mac, or many others). In such a market situation, w-o-m mechanism is analyzed and it involves the exchange of information on competing products, which are already on the market.

The study used two-dimensional cellular automaton in which the environment affects the central agent, the information flows inward. The influence of introduced mobility of agents on the behaviour of the model for different degrees of agent's density was precisely studied together with the impact of the neighbourhood size of a single agent.

A detailed description of the model parameters, the local decision rules and the course and results of simulations are shown in the following sections.

\section{Proposed model}

Our research concerns the behaviour of consumers. We have been studying the environment of consumers, so that the model is presented as a square lattice of size L x L with periodic boundary conditions. Each $\mathrm{i}$-th cell $\left(\mathrm{i}=1,2, \ldots \mathrm{L}^{2}\right)$ can be in one of three states: empty $(\mathrm{Si}=0)$, occupied by an agent of type $\mathrm{A}(\mathrm{Si}=1)$ or occupied by an agent of type $\mathrm{B}$ $(\mathrm{Si}=-1)$. In this paper, the cells occupied by the agents in lattice, correspond to consumers. Types A and B are defined as consumers of the two competing firms products. Initially agents are distributed randomly on the lattice, i.e. with probability $p \in[0,1]$ a cell is occupied, and with probability $1-\mathrm{p}$ it is empty. Probability $\mathrm{p}$ is simply an average concentration of agents but on the other hand, it can be interpreted as an access to information in word of mouth marketing.

Let us denote by $\mathrm{N}$ the total number of agents: 


$$
N=p L^{2}
$$

$\mathrm{N}_{\mathrm{A}}$ denotes the number of A-agents and $\mathrm{N}_{\mathrm{B}}=\mathrm{N}-\mathrm{N}_{\mathrm{A}}$ number of B-agents. We introduce the concentration of A-agents as $\mathrm{c}=\mathrm{N}_{\mathrm{A}} / \mathrm{N}$ and thus the concentration of $\mathrm{B}$-agents is equal $1-\mathrm{c}$.

At each time step $t$, all cells $i=1, \ldots, \mathrm{L}^{2}$ are updated simultaneously (typical cellular automata approach [2]) according to the following local rules:

- Agent checks the preferences of its neighbourhood, and changes its preference for the dominant in the neighbourhood (i.e., if more than $50 \%$ of its neighbours have a different opinion than it, then it changes its opinion on the dominant one).

- If more than $50 \%$ have the same opinion as the test agent, of course, nothing changes.

- If there is no dominant preference in the agent neighbourhood, then the agent moves to the nearest empty place in one of four directions N, E, S,W (north, east, south and west). The orientation is randomly assigned for each agent at the beginning of the simulation.

Defining the cellular automaton this way, we usually take into account effects of interpersonal influence and possibility of agent's movement. Possibility of consumer's movement to the lattice, distinguishes the proposed model of the known models of marketing such as $[7,16,18]$ and [19-21]. Consumer mobility is an important assumption, because by changing place in lattice the actual consumer behaviour can be mapped, which may yet in situations of uncertainty discuss its decision with another group of people (this may mean first consultation in the family, then in a group of friends and / or use of the Internet for example).

These rules of agents (defined above) have already been used in the paper [22]. Cited paper proposed a simple microscopic model of consumer behavior in which decisions are made solely on the basis of person to person communication. In this study, dynamics of consumers preferences changes, which are modified by w-o-m mechanism, is examined. $\mathrm{W}-\mathrm{o}-\mathrm{m}$ communication is most effective when it is in the nearest neighborhood (family, group of friends). In this paper, family or group of friends is represented by the von Neumann's neighborhood (see Fig. 1 and Fig. 2). Because family or group of friends contain a different number of members (the number of w-o-m information sources is diverse), the von Neumann's neighborhood for $r=2$ also is used. Moreover, the various density of filling lattice (population density) is proposed. In this situation, the von Neumann's neighborhood for the agent/consumer may consist of from 0 to 4 when $r=1$ and from 0 to 12 people when $r=2$. This assumption is a step in the direction of better social reality reflection by the $\mathrm{CA}$ model, where the nearest neighborhood is composed of varying numbers of people. 


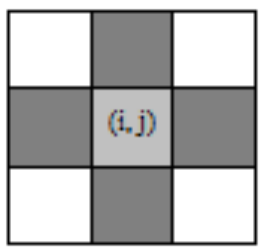

Figure 1. Von Neumann's neighborhood of a two-dimensional automaton cell (i, $\mathbf{j})$ with $r=1$ (neighborhood 4-element)

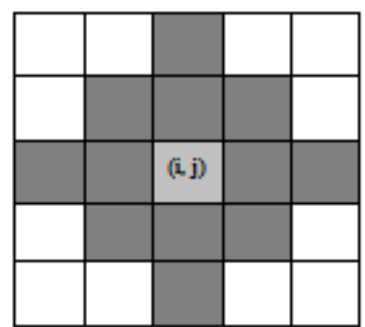

Figure 2. Von Neumann's neighborhood of a two-dimensional automaton cell $(i, j)$ with $r=2$ (neighborhood 12-element)

\section{Simulation experiments}

\subsection{Experiments' project}

The proposed modified model was subjected to simulation studies. These studies were designed to investigate the properties of the modifications that have been used to reflect actual market processes. Agents/consumers in our study could choose between the products of the two competing firms. Characteristics of this dynamic in relation to the changing parameters of the model was the subject of designed experiments.

Experiments were performed to investigate the dynamics of preferences in relation to the products of the two competing firms, changing the nature of mobility agents, and the type and amount of information sources 'word of mouth' (environment), by stepwise changes in parameter settings:

- $\mathrm{p}$ - population density,

- $\mathrm{L}-$ size of the lattice.

For the simulations results, the standard deviation $\left(\mathrm{Dc}_{\mathrm{st})}\right.$ of the stationary concentration of A-agents $\left(\mathrm{c}_{\mathrm{st}}\right)$ was calculated. It is the standard deviation of the average number of Aagents, after obtaining a stable state. Results are averaged over 1000 samples. Stable state is a state where, no agent changes its preference and place in the lattice. 
The standard deviation was analyzed, because this is one of the key risk measures in the field of finance and economics. Such a measure can be associated with the risk, which exists in the process of maintaining a stable relationship in the market, which is divided between two brands of the product (i.e. the risk of changes of preferences, in the analyzed society).

Because the proposed modifications to the traditional CA model in market research relied primarily on the potential movement of agents on the lattice, experiments were also carried out without agents movement. The results of comparative experiments are discussed in the next section.

\subsection{Simulation results}

In the simulations, consumers had a choice of products of two competing firms (A and B). Furthermore, it was assumed that the number of consumers who prefer A- firm products is the same as consumers who prefer B- firm products $(c=0,5)$.

It was first examined, how a change of $\mathrm{L}$ - the size of the lattice, affects the behaviour of consumer society. The standard deviation of the number of consumers who prefer option A from the initial state $(c=0,5)$ for the 1000 simulation (Monte Carlo Simulations) was analysed.

Figures 3, 4, 5 and 6 show the dynamics of preferences for the simulation involving 1000 samples, depending on the size of the lattice for two population density: $p=0,3$ and $p$ $=0,7$ (i.e. small and large $p$ ).

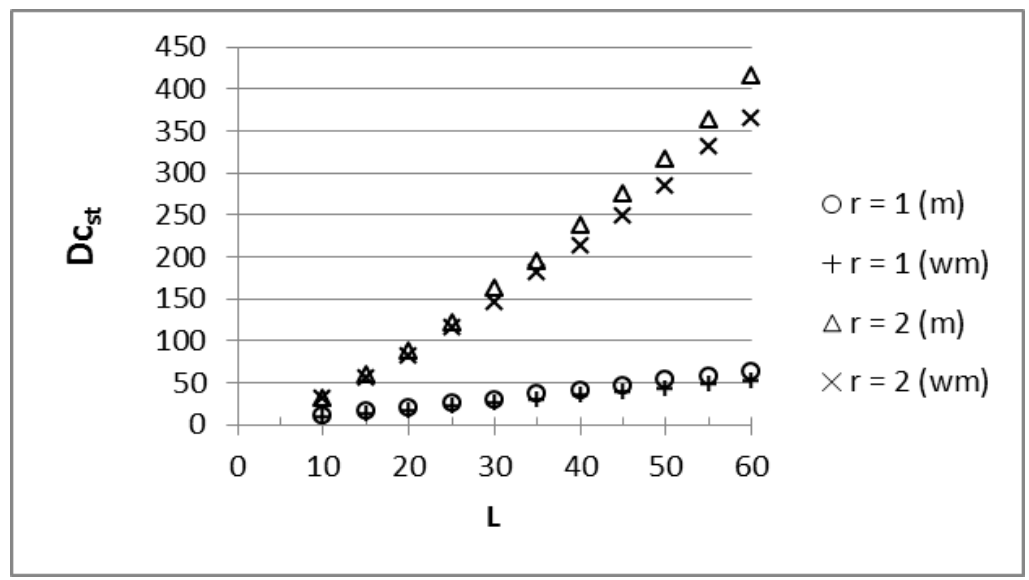

Figure 3. Standard deviation of the stationary concentration of A-agents $D c_{\text {st, }}$ as $L$ function, for $p=0,7$; model with movement $-(\mathrm{m})$, model without movement $-(\mathrm{wm})$ 


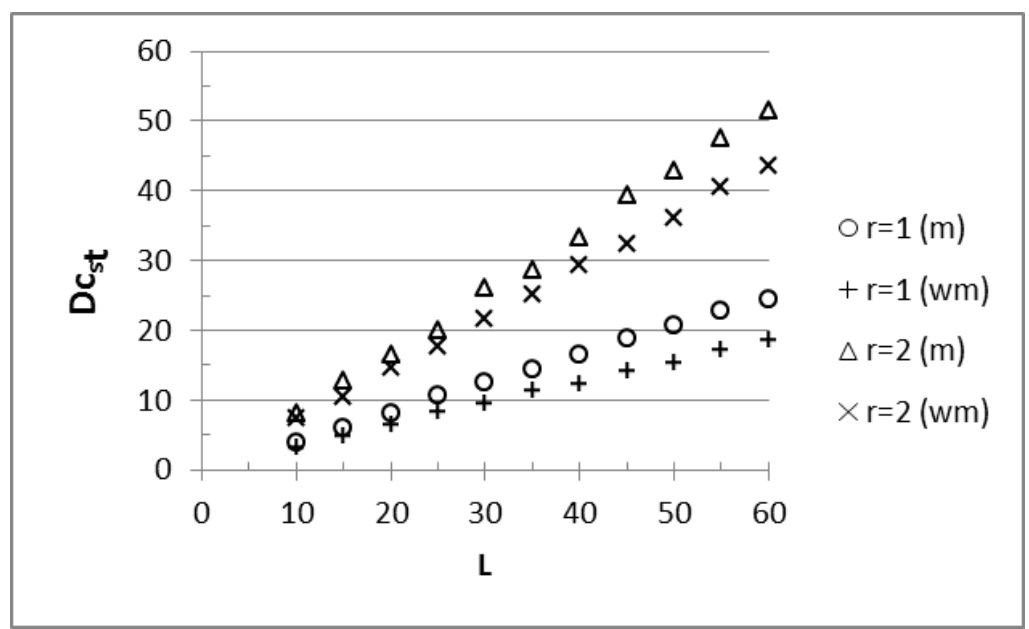

Figure 4. Standard deviation of the stationary concentration of A-agents $D c_{\text {st }}$, as $L$ function, for $p=0,3$; model with movement $-(\mathrm{m})$, model without movement $-(\mathrm{wm})$

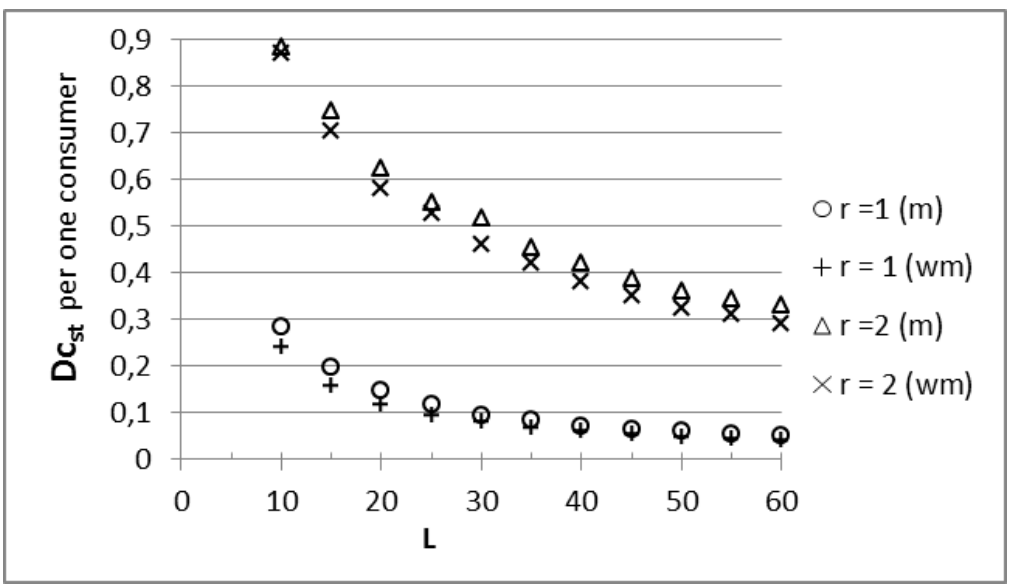

Figure 5. Standard deviation of the stationary concentration of A-agents De $c_{\text {st }}$ per one consumer, as $L$ function, for $p=0,7$; model with movement $-(\mathrm{m})$, model without movement $-(\mathbf{w m})$ 


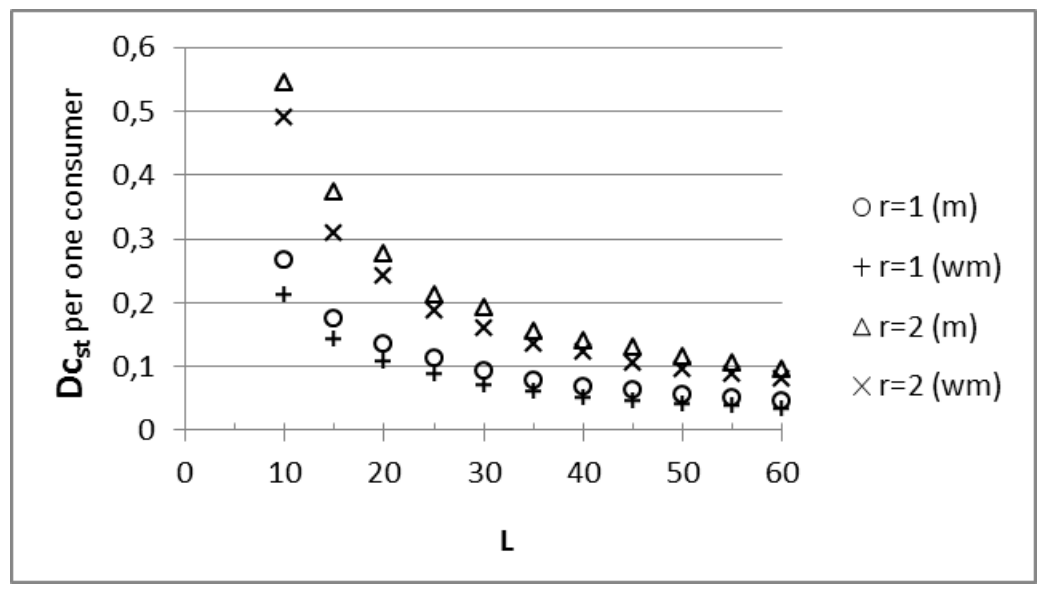

Figure 6. Standard deviation of the stationary concentration of A-agents Dest per one consumer, as $L$ function, for $p=0,3$; model with movement $-(m)$, model without movement $-(\mathbf{w m})$

In these experiments, standard deviation of the stationary concentration of A-agents (for $\mathrm{c}=0,5$, or $50 \%$ for $\mathrm{A}$ and $50 \%$ for $\mathrm{B}$ ) was taken as a indicator. As mentioned earlier, this is one of the fundamental measures of risk. In this case, it is a measure of risk of instability of preferences on the market, which is divided between two products. The graphs on Fig. 3 and Fig. 4 show the almost linear relationship between the size of the lattice and the size of the calculated deviation. Subsequently, the standard deviations shown in Fig. 3 and Fig. 4 are divided by the number of consumers at the beginning of the simulation, and the standard deviation per one consumer has been calculated (see Fig. 5 and Fig. 6). As you can see, the general trend of behavior suggests that the w-o-m mechanism leads to more stable behavior in larger communities (the larger the network, the smaller the deviation). Large impact on the dynamics of preferences has the size of the examined groups, within which opinions are confronted and formulated. These groups are represented respectively by the neighborhood of radius $r=1$ and $r=2$. Larger groups of colleagues/friends cause the overall increase in risk of preferences changes. These risks are also modified by the opportunity to consult with other sources of information (modelled by the movement of the agent). Possibility to seek opinion in a larger number of neighbors clearly affects the behavior of agents (see Fig. 3, 4, 5, 6). The availability of additional sources of information (movement) has an impact only in the case of smaller density $(p=0,3)$.

Then, the influence population density of the lattice on consumer behavior has been studied. Fig. 7 shows the results of preferences changes for the lattice of fixed size $L=20$ for the parameters described above. Similar results are obtained for larger L, however, due to the large number of experiments and the duration of the simulation, the results are presented for $\mathrm{L}=20$. 


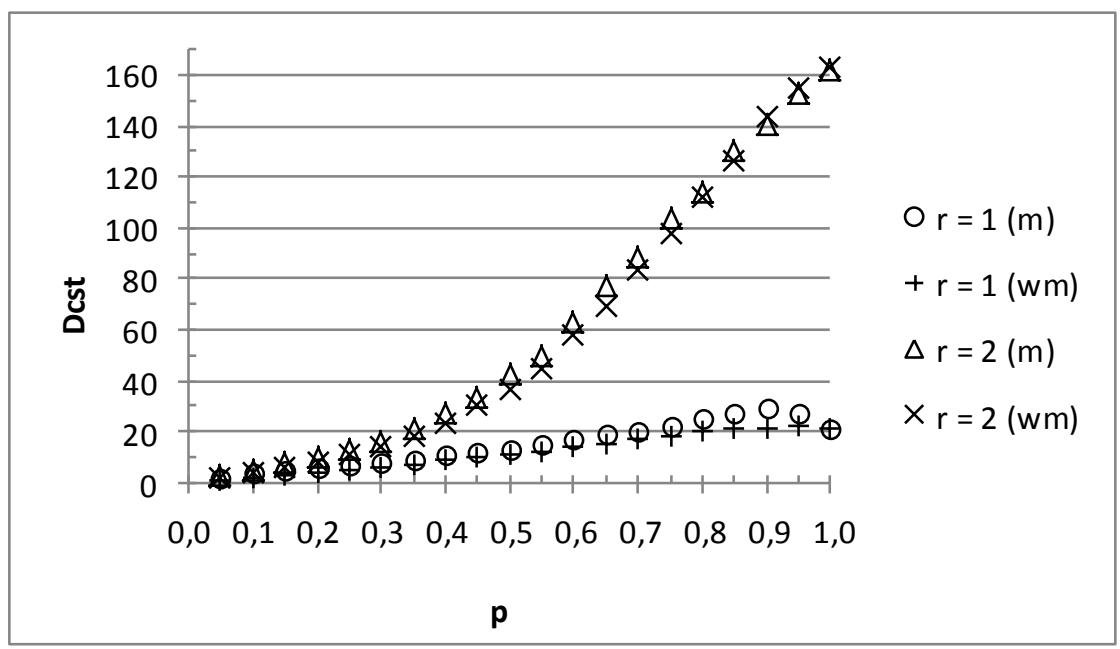

Figure 7. Standard deviation of the stationary concentration of A-agents $\mathrm{Dc}_{\mathrm{st}}$, as $\mathbf{p}$ function, for $L=20$; model with movement $-(\mathrm{m})$, model without movement $-(\mathrm{wm})$

As shown in Fig. 7 the risk of preferences changes is very much dependent on the size of neighborhood radius. Larger number of contacts, in the w-o-m mechanism, causes much greater risk of changes for the average consumer group representative. This risk increases along with the population density of the lattice i.e. the size of the communities represented by the lattice. The possibility of diversifying the sources of information (movement in the opinion space) is marginal, although the movement acts a bit destabilizingly on the level of average deviations. An interesting phenomenon, for all variants of experiments carried out for different population densities and different neighborhoods (for $r=1$ and $r=2$ ) in models with and without movement, is a kind of 'segregation' of agents - as in Schelling's model [23]. A model for self-forming neighborhoods proposed by Schelling was used in the paper of Kowalska-Styczeń [24] to simulate consumers behavior. Although, the model presented in this paper does not presume segregation, consumers/agents show noticeable tendency to form groups with the same preferences (see Table 1). This phenomenon is better explained in paper [22]. Table 1. shows examples of simulation results from a random initial state to a stable state for $\mathrm{L}=20$ and $\mathrm{c}=0.5$, where black and grey indicate $\mathrm{A}$ and B-type consumers, and white indicates an empty cell. These results are an example of a single simulation. The standard deviation in Fig. 3, 4, 5, 6 was calculated for 1000 such simulations (samples) and for different lattice sizes L. In the Table 1, an example for $\mathrm{L}=20$ is presented. Simulations for other $\mathrm{L}$ give similar images. For both $\mathrm{p}=0,3$ and $\mathrm{p}=0,7$, and for different neighborhood sizes $(\mathrm{r}=1$ and $\mathrm{r}=2)$, agents/consumers show a tendency to form consumers clusters, having the same preferences. 
Table 1.

\begin{tabular}{|c|c|c|c|}
\hline & initial state & $\begin{array}{c}\text { stable state for } \\
\qquad r=1\end{array}$ & $\begin{array}{c}\text { stable state for } \\
\qquad r=2\end{array}$ \\
\hline 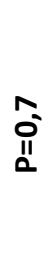 & r & 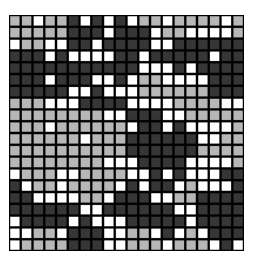 & , \\
\hline $\begin{array}{l}\text { ma } \\
\text { ó } \\
\text { a }\end{array}$ & r & s, & r. \\
\hline
\end{tabular}

\section{Conclusion}

The proposed model is, like any other model, a simplification of reality. In the analyzed experiments, however, it was shown that results obtained by such simplifications confirm the intuitive belief. Experiments were performed to investigate the dynamics of preferences changes in relation to the products of two competing firms, changing the nature of agents mobility, and the type and amount of w-o-m information sources. It was examined how the change of lattice size (population size) and the population density, affects the risk of preferences changes on the two competing firms market. Simulations have been carried out for two neighbourhood sizes (smaller, when $r=1$ and larger, when $r=2$ ). In this study, a standard deviation of the number of votes for A from the initial state was assumed as a risk measure. Nature of agents mobility, and the type and amount of w-o-m information sources, was changed.

Generally, this risk of preferences change decreases with the size of the lattice, and increases with the population density (so with the potential number of possible contacts). In larger communities, the preferences changes (modified by w-o-m mechanism) are more stable (larger lattice, smaller deviation). Therefore, it is more difficult to prompt larger communities to change preferences. The dynamics of these processes is strongly affected by the size of the nearest neighborhood - that is, the number of w-o-m contacts. Larger quantities of these contacts, cause an increased risk of preferences changes, but also, on the other hand, greater tendency to change. The possibility to consult other information sources (agents movement), influences the risk, but to a much lesser extent. The amount of 
additional contacts, obtained by this mechanism, is relatively small in comparison to neighborhood size change, when altering $r=1$ to $r=2$.

It seems that, the preliminary results obtained in this article, generally confirm the potential of rather simple tool, which is the cellular automata. The study of the structure networks presented in this article, as shown by numerous studies [25, 26], is very interesting. In paper [25] the authors conclude, that the companies are not fully aware of channels structure of communication with consumers. Also Bohlmann at al. [26] postulated that managers should pay particular attention to the network structure, because their understanding and understanding of the communication influence will enable the companies to make marketing decisions more rationally. In future studies, the model can be used to such a study. It is very interesting, how the structure of the network affects the consumers preferences changes. So, the structural network parameters (contacts numbers, groups diversity, possibility to change the source of information) can be more widely analyzed. This can be used for a better understanding of market processes, and thereby assist in the development of more efficient and effective marketing campaigns.

\section{Acknowledgments}

The work was supported by funds from the National Science Centre (NCN) through grant no. $2011 / 01 / \mathrm{B} / \mathrm{HS} 4 / 02740$.

\section{References}

[1] Sarkar P., A brief history of cellular automata, ACM Computing Surveys, 32 (1), 2000, $80-107$.

[2] Wolfram S., A New Kind of Science, Wolfram Media, Inc., 2002.

[3] Kowalska - Styczeń A.: Simulation of complicated economic processes with the use of cellular automatons. Wydawnictwo Politechniki Śląskiej, Gliwice, 2007 (in Polish).

[4] Macy M.W., Willer R., From factors to actors: Computational sociology and agentbased modeling, Annual Review of Sociology 28, 2002, 143-166.

[5] Rand W., Rust R. T., Agent-based modeling in marketing: Guidelines for rigor, International Journal of Research in Marketing, Volume 28, Issue 3, 2011, 181-193.

[6] Peres R., Muller E., Mahajan V., Innovation diffusion and new product growth models: A critical review and research directions, International Journal of Research in Marketing 27, 2010, 91-106.

[7] Goldenberg J., Libai B., Muller E., Using Complex Systems Analysis to Advance Marketing Theory Development: Modeling Heterogeneity Effects on New Product Growth through Stochastic Cellular Automata, Academy of Marketing Science Review 9, 2001.

[8] Goldenberg, J., Efroni S., Using Cellular Automata Modeling of the Emergence of Innovations, Technological Forecasting and Social Change, 68 (3), 2001, 293-308. 
[9] Moldovan S., Goldenberg J., Cellular automata modeling of resistance to innovations: Effects and solutions, Technological Forecasting and Social Change, 71, 2004, 425442.

[10] Mahayan V., Muller E., Kerin R. A., Introduction strategy for new products with positive and negative word-of mouth, Management Science, 30, 12, 1984, 1389

[11] Brown J. J., Reingen P. H., Social Ties and Word-of-Mouth Referral Behavior, Journal of Consumer Research, 14, 1987, 350 - 362.

[12] Hennig-Thurau, T., Walsh, G., Electronic word-of-mouth: motives for and consequences of reading consumer articulations on the Internet, International Journal of Electronic Commerce, 8, 2, Winter, 2004, 51-74.

[13] Steffes E. M., Burgee L. E., Social ties and online word of mouth, Internet Research, 19, 1, 2009, 42-59.

[14] Goldsmith R.E., Horowitz D., Measuring motivations for online opinion seeking, Journal of Interactive Advertising, 6, 2, Spring, 2006, 1-16.

[15] Godes D., Mayzlin D., Firm-Created Word-of-Mouth Communication: Evidence from a Field Test, Marketing Science, 28, 4, 2009, 721-739.

[16] Goldenberg J., Libai B., Muller E., Talk of the Network: A Complex Systems Look at the Underlying Process of Word-of-Mouth, Marketing Letters, 12:3, 2001, 211 - 223.

[17] Moldovan S., Goldenberg J., Chattopadhyay A., The different roles of product originality and usefulness in generating word-of-mouth, International Journal of Research in Marketing, 28, 2011, 109-119.

[18] Goldenberg J., Libai B., Muller E., Riding the Saddie: How Cross-Market Communications Can Create a Major Slump in Sales, Journal of Marketing, 66, 2002, 1-16.

[19] Garber, T., Goldenberg, J., Libai, B., Muller E., From Density to Destiny: Using Spatial Dimension of Sales Data for Early Prediction of New Product Success, Marketing Science, 23, 3, 2004, 419-428.

[20] Goldenberg J., Libai B., Muller E., The chilling effects of network externalities, International Journal of Research in Marketing, 27, 2010, 4-15.

[21] Ma F., Chao G., Research on Communication Products Diffusion in China Using Cellular Automata, International Business Research, 4, 2, 2011, 147 - 152.

[22] Kowalska-Styczeń A., Sznajd-Weron K., Access to information in word of mouth marketing within a cellular automata model, Advances in Complex Systems, 15, 7, 2012, 1250080 (17 pages).

[23] Schelling, T., Dynamic models of segregation, Journal of Mathematical Sociology, 1, 1971, 43-186.

[24] Kowalska - Styczeń A., Model symulujący podejmowanie decyzji przez konsumentów, Badania Operacyjne i Systemowe: Decyzje, Gospodarka, Kapitat Ludzki i Jakość, seria Badania Systemowe, 64, Warszawa, 2008, 227-236 (in Polish).

[25] Alkemade F., Castaldi C., Strategies for the diffusion of innovations on social networks, Computational Economics, 25, 1, 2005, 3-23.

[26] Bohlmann J. D., Calantone R. J., Zhao M., The Effects of Market Network Heterogeneity on Innovation Diffusion: An Agent-Based Modeling Approach, Journal of Product Innovation Management, 27, 2010, 741-760.

Presented at the XII Conference: Systems and Operational Research - BOS 2012, 17-19 September 2012, Warsaw, Poland 